\title{
SUICIDAL PACT AMONGST THREE SCHOLAR ADOLESCENTS SEEN IN EMERGENCY ROOM-LIMA
}

Author: Vásquez F, Villar A. NIMH Lima - Peru, National Institute of Mental Health, Lima Peru.

DISCLOSURE: No conflict of interest.

OBJECTIVE: Describe suicidal attempt in 3 scholar adolescents of the same room of a high school of Lima, seen in Psychiatric Emergency Room services in April 2018.

BACKGROUND AND AIMS: In adolescence there is a high vulnerability for suicidal behaviour, especially in scholar milieu, also adverse familial events and depression behind.

MATERIAL and METHODS: Descriptive trial, by using Clinical Histories, relative versions, Pierce Scale for Sucidal Behavior, mass media as well as Social net information.

RESULTS: It was founded suicidal attempt in 3 adolescents of 16 years old average, from Fourth degree of the same Class and High School: One of them jumped from third block of own College, while other 2 made self-cut and took drug overdose the same day. They were sending messages by Internet and Social net for provoking suicide, trying to coordinate the day, time and way of suicide. First adolescent suffered Severe Skull Trauma and conducted to a Critical Unit of a local Hospital and remains in coma state so far, while other 2 were referred to a Psychiatry Emergency Rooms. As a precedent, the first adolescent lost his father by Cancer 3 months ago; other two live in disgregated and dysfunctional families. All 3 adolescents showed depressive symptoms and had been victims of bullying at school.
CONCLUSIONS: According study, this happening is compatible with Suicidal Pact amongst 3 scholar adolescents of the same Room and High School, and one of them was about complete suicide, because of accumulation of risk factors and vulnerability described for adolescence.

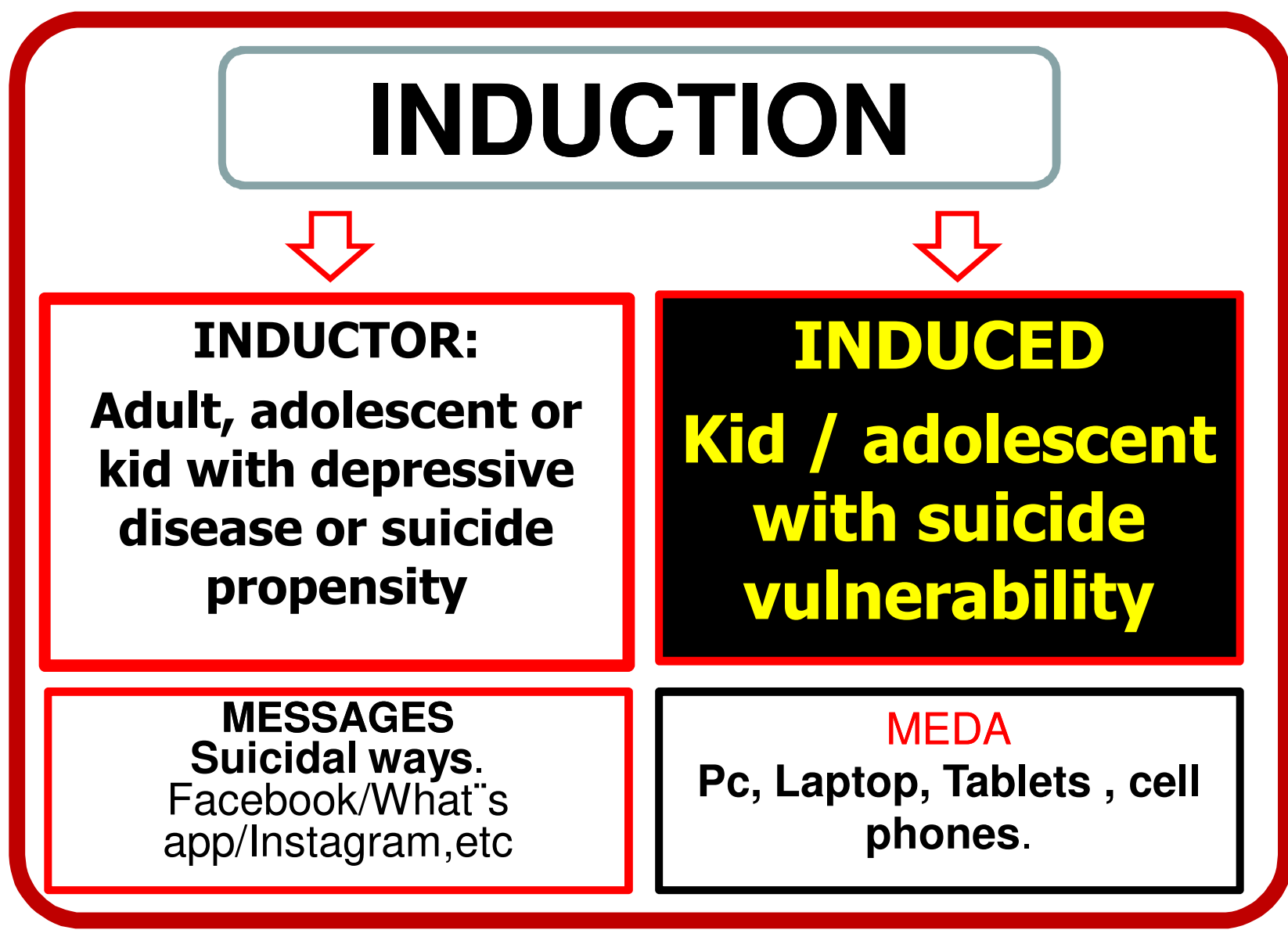

Suicide attempt - Schools of Lima 2017-2018

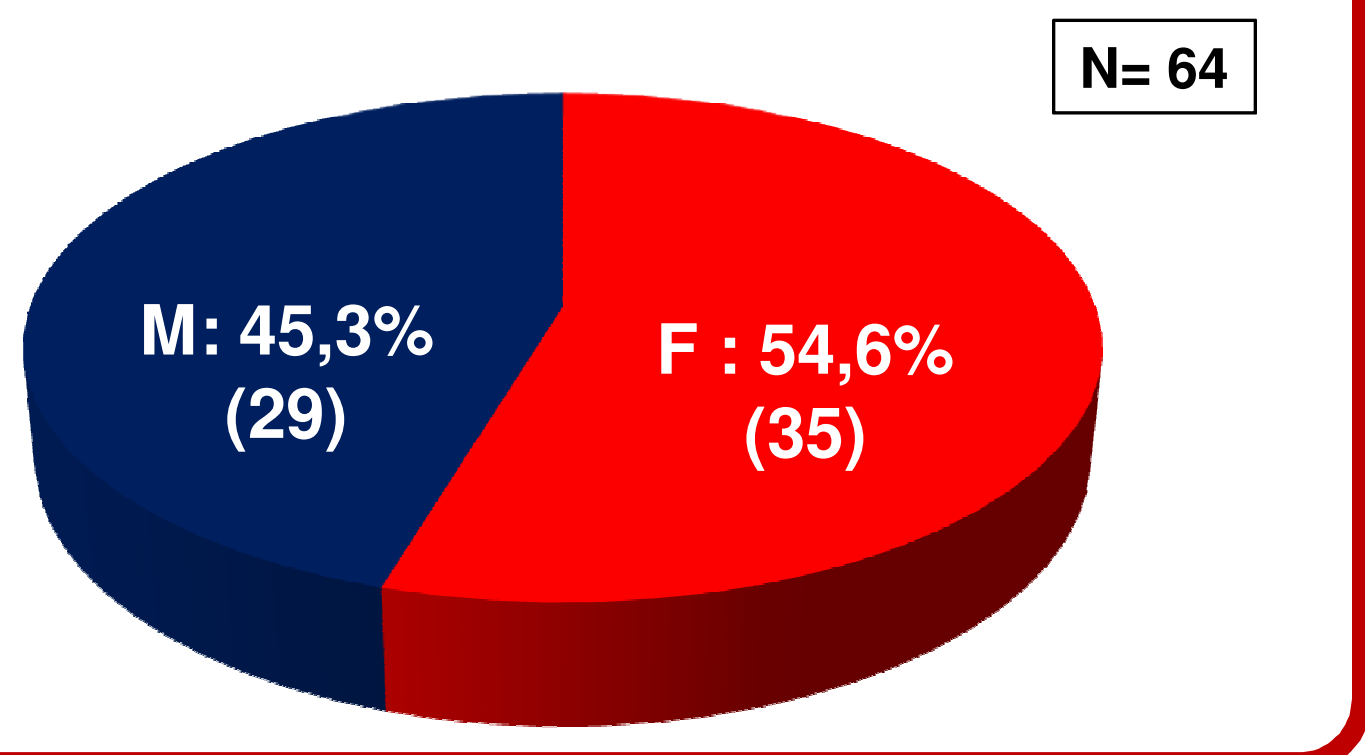

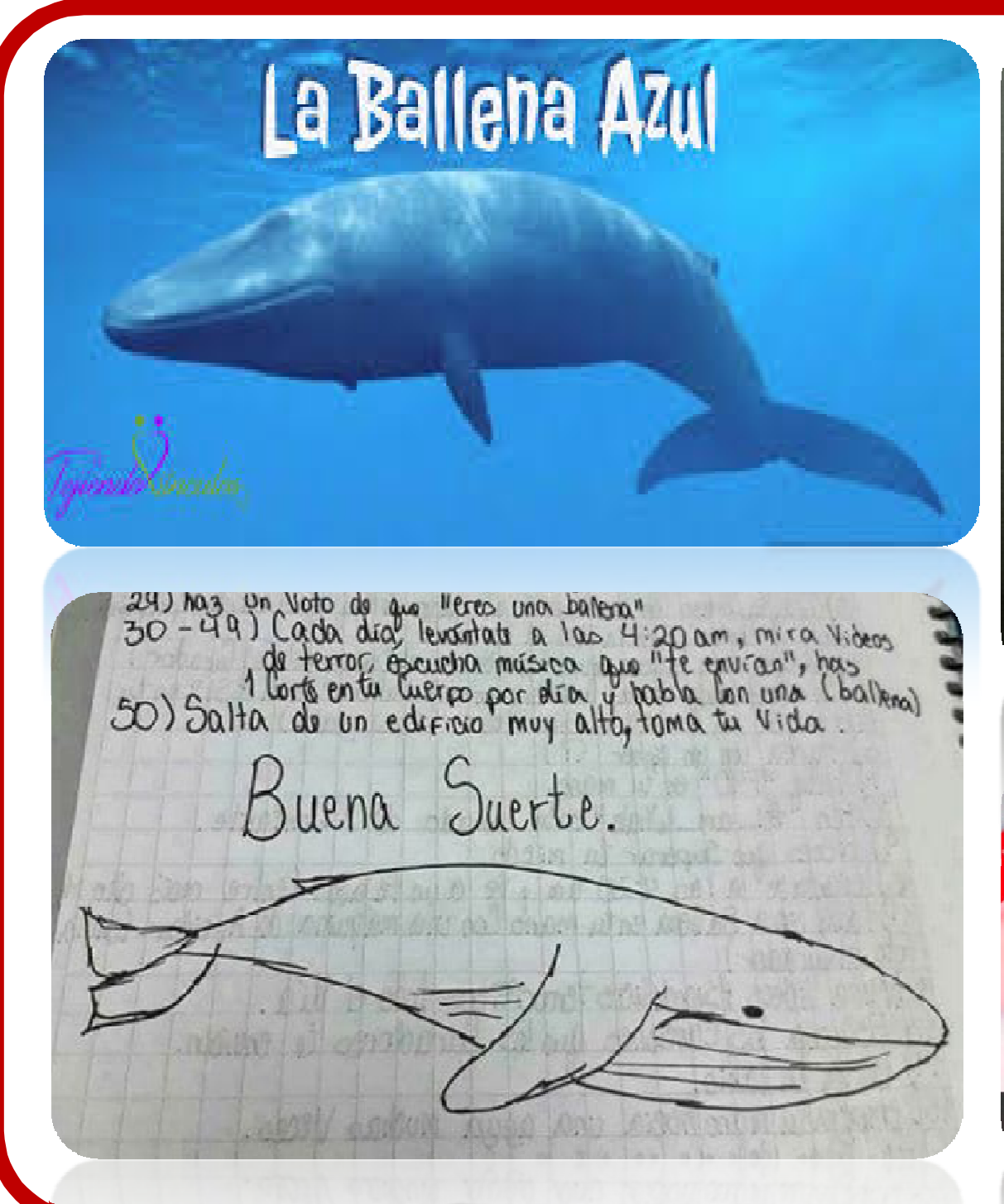
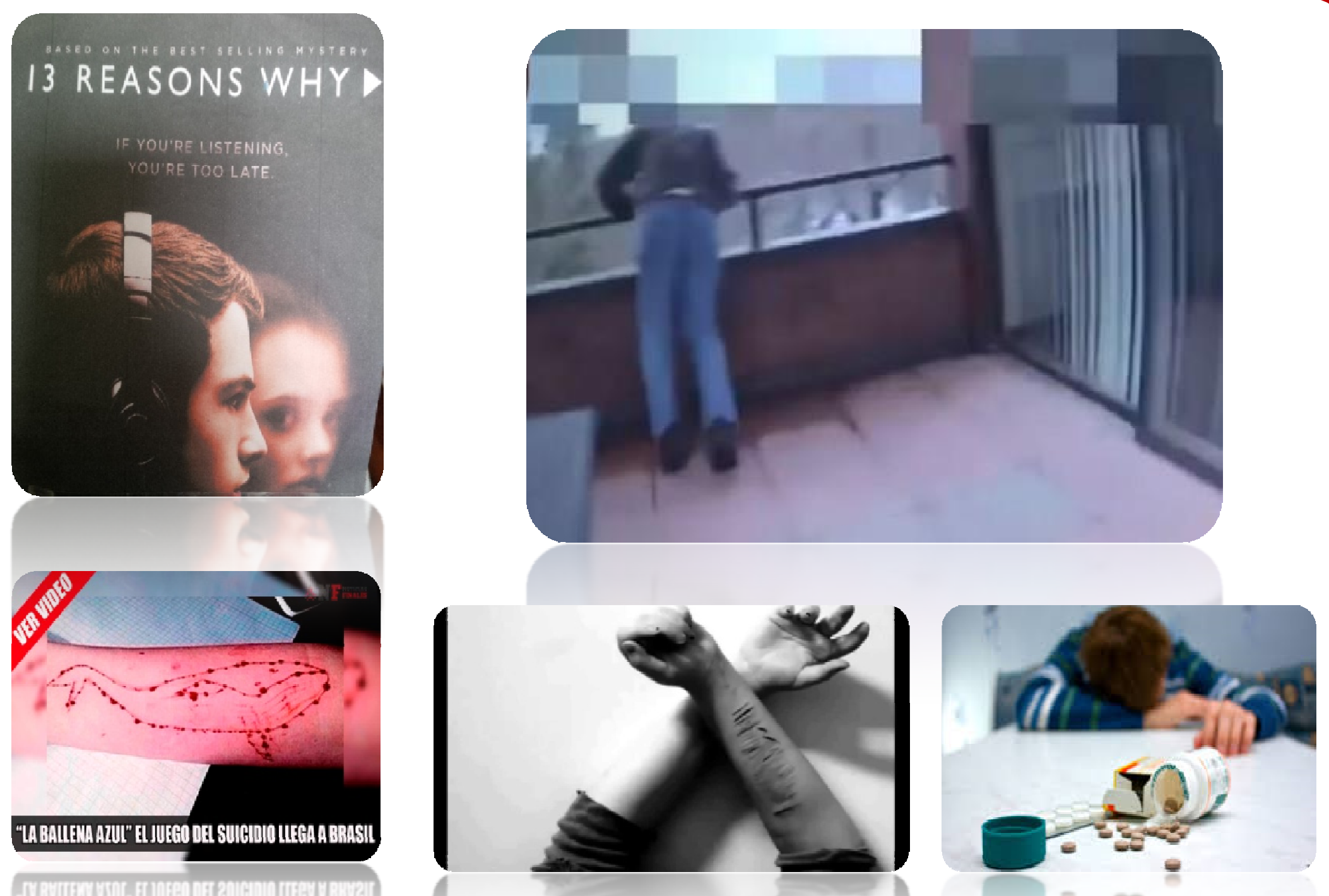

Fernández JJ, Basile H., Pérez Barrero S., 2017 Suicidio Infanto Juvenil. Mitos y verdades de un gran problema de Salud Pública. Editorial Palermo.

SAMSA, 2015 Preventing Suicide. A toolkit of High School US Department of Health and Center of Mental Health and Human Services. USA. 